\title{
Allelopathic effect of Morus alba, Populus nigra and Euphorbia helioscopia on Brassica campestris
}

\author{
Shah Khalid ${ }^{*}$, Amreen ${ }^{1}$, Somaeeya Bibi ${ }^{1}$, Syeda Asma Taskeen ${ }^{1}$, Hoor \\ Shumail ${ }^{2}$ and Syed Inzimam Ul Haq ${ }^{1}$ \\ 1. Department of Botany, Islamia College Peshawar, KPK-Pakistan \\ 2. Department of Microbiology, Women University Mardan, KPK-Pakistan \\ *Corresponding author's email: shahkhalid@icp.edu.pk \\ Citation \\ Shah Khalid, Amreen, Somaeeya Bibi, Syeda Asma Taskeen, Hoor Shumail and Syed Inzimam Ul Haq. Allelopathic \\ effect of Morus alba, Populus nigra and Euphorbia helioscopia on Brassica campestris. Pure and Applied Biology. \\ Vol. 10, Issue 2, pp532-538. http://dx.doi.org/10.19045/bspab.2021.100056
}

Received: 02/07/2020

Revised: $26 / 09 / 2020$

Accepted: 03/10/2020

Online First: 20/10/2020

\section{Abstract}

The current research work investigates the allelopathic potential of leaves of most common plants found in Brassica farms i.e. Morus alba, Populus nigra and Euphorbia helioscopia on seed germination and seedling growth of Brassica campestris. Fresh and dry leaves of M. alba, P. nigra and E. Helioscopia was prepared by soaking fresh chopped leaves and dry leaves in powder form $(5 \mathrm{~g}, 10 \mathrm{~g}$ and $15 \mathrm{~g})$ were soaked in $100 \mathrm{ml}$ of distilled water for $48 \mathrm{hrs}$ and were filtered after $24 \mathrm{hrs}$. The extract of M. alba, P. nigra and E. helioscopia was applied on B. campestris seeds to study its effect on germination percentage, radicle length and plumule length. The data was recorded in triplicates after $72 \mathrm{hrs}$ of the incubation period at $26^{\circ} \mathrm{C}$. Extracts of $M$. alba and P. nigra significantly reduced the germination percentage while E. helioscopia enhanced the germination percentage of $B$. campestris. The results revealed that the most effective treatment was $10 \mathrm{~g}$ fresh leaves extract of $P$. nigra which reduced the germination to $67 \%$ and showed no germination in $15 \mathrm{~g}$ fresh leaves extract. The fresh and dry leaves extract of M. alba, P. nigra and E. helioscopia reduced the radicle and plumule length. Maximum reduction in the radicle length was recorded 95.41\% in 10g fresh leaves extract of Populus nigra and maximum reduction in plumule length was recorded $95.49 \%$ in $15 \mathrm{~g}$ dry leaves extract of Euphorbia helioscopia. The effect of dry leaves extract was more inhibitory effect than the fresh leaves extract. From the results it was concluded that the fresh and dry leaves extract of M. alba, P. nigra and E. helioscopia negatively affected the germination and seedling growth of Brassica campestris which indicates that some allelochemicals might be present in these plants.

Keywords: Allelopathic effect, Brassica campestris; Euphorbia helioscopia; Germination percentage; Inhibitory effect; Morus alba, Populus nigra; Plumule length; Radicle length

\section{Introduction}

The term allelopathy was originated from two Greek words, allelo means each other and pathy means to suffer. The term allelopathy was first used by the Austrian Professor Hans Molisch in his book. He used this term to describe biochemical interaction that inhibits the growth of neighboring plants 
by another plant. The biological phenomenon by which an organism produces one or more biochemicals that influence the growth, germination and survival of another organism is known as Allelopathy [1]. Rice [2] used the term allelopathy as "any direct or indirect harmful or beneficial effect by one plant on another through the production of chemical compounds that escape into the environment". These chemical compounds produced by an organism may have positive, negative or both positive and negative effect. Allelochemicals are those chemicals which can cause allelopathy. These chemicals are secondary plant compounds that are released into the surrounding. Allelochemicals are a wide class of compounds that ranges from simple hydrocarbon to complex polycyclic compounds. Allelochemicals can lead to a different mechanism of action in plants. An allelopathic effect is mainly referred to as a type of negative interaction $[3,4]$ but positive interaction has also been reported depending on the allelochemicals considered the target plant and the concentration tested [5]. Morus alba L. is known as white mulberry is a fast growing small to medium sized tree belonging to the family Moraceae. It grows up to $10-20 \mathrm{~m}$ tall. The leaves of Morus alba are simple, alternate, serrate or dentate and 27 inches long. The life span of white mulberry is long-life. In Greece, there are records of 150-year-old white mulberry trees [6]. Populus nigra commonly known as safeda is a dioecious tree. It grows at a faster rate and matures in 10-15 years. It is a tree and belongs to the family Salicaceae having a height up to 35 meters with dull grey bark. The plant has a good quality of regeneration due to its rapid growth. Dispersal of seeds occurs by wind and water. It grows and regenerates well in moist conditions [7]. Brassica campestris commonly known as mustard and belongs to family Brassicaceae (Cruciferae). It is an annual herb and there are 40 species of $B$. campestris that is distributed in the Mediterranean region. There are 7 species of $B$. campestris in Pakistan. Between these species only two are wild and the other is cultivated [8]. Hussain [9] studied the allelopathic suppression of wheat and mustard by Rumex dentatus with aqueous extracts of rain leachates, litter from fresh and dried shoots and roots. The aqueous extracts of Rumex dentatus were highly inhibitory to the germination and seedling growth of both the crops. Lopez [10] investigated that Tagetes minuta contains some chemicals in its leaves due to which they show the allelopathic effect. They showed that pure ocimenones delayed and caused inhibition in the seed germination of coexistence species.

\section{Materials and Methods}

The present study investigates the allelopathic potential of M. alba, P. nigra and $E$. helioscopia extract on germination percentage, plumule and radicle length of $B$. campestris. Leaves of $M$. alba, P. nigra and $E$. helioscopia were collected. From the collected leaves, half leaves were crushed directly with the help of mortar and pestle and half were dried in the shade.

\section{Relative toxicity of plant}

Aqueous extracts of fresh and dried leaves of M. alba, P. nigra and E. helioscopia were prepared by soaking $5 \mathrm{~g}, 10 \mathrm{~g}$ and $15 \mathrm{~g}$ of fresh and dry leaves separately in $100 \mathrm{ml}$ of distilled water for 48 hours at room temperature. The extract was then filtered after $24 \mathrm{hrs}$ and was stored in a refrigerator for future use. Distilled water was used as a control treatment. Petri dishes were lined with doubly folded Whatman No.1 filter paper. The viability of seeds $B$. campestris was checked. Each Petri dish was provided with 5 healthy seeds and was placed at an equal distance on the filter paper. The seedbed was moistened with 4-5 drops of plant extract and in case of control plant was moistened with distilled. These petri dishes were placed in an incubator at $26^{\circ} \mathrm{C}$ for 72 hours. Each treatment and control had 3 
replicates. After 72 hours of incubation germination percentage, radicle and plumule length, were recorded.

\section{Statistical analysis}

The experiment was performed in triplicates. The data obtained was statistically analyzed by using one-way ANOVA followed by LSD test at $\mathrm{P}=0.05$.

\section{Results}

\section{Germination percentage (\%)}

The germination percentage of B. campestris was significantly decreased by $M$. alba and $P$. nigra extracts and was significantly increased by E. helioscopia extract, as shown in (Fig. 1). The results showed that the maximum decline in germination percentage was recorded $40 \%$ in $15 \mathrm{~g}$ dry leaves extract of $M$. alba whereas minimum inhibition was recorded $11.15 \%$ in $5 \mathrm{~g}$ fresh leaves extract. $P$. nigra $15 \mathrm{~g}$ fresh leaves extract showed no germination while showed maximum germination $(67 \%)$ in $10 \mathrm{~g}$ fresh leaves extract and minimum germination (14\%) in $5 \mathrm{~g}$ fresh and $10 \mathrm{~g}$ dry leaves extract whereas no change was observed in $5 \mathrm{~g}$ and $15 \mathrm{~g}$ dry leaves extract. The extract of E. helioscopia enhanced the germination percentage and was recorded maximum $(33.33 \%)$ in $15 \mathrm{~g}$ fresh leaves extract and minimum (22.21\%) in $15 \mathrm{~g}$ dry leaves extract, while inhibited the germination percentage up to $11.16 \%$ in $5 \mathrm{~g}$ fresh and $15 \mathrm{~g}$ dry leaves extract.

\section{Radicle length $(\mathrm{cm})$}

The extract of $M$. alba, $P$. nigra and $E$. helioscopia significantly reduced the radicle length of B. campestris is shown in (Fig. 2). The graph showed that maximum reduction in the radicle length was recorded $75.57 \%$ in $5 \mathrm{~g}$ fresh leaves extract and minimum reduction in radicle length was recorded $61.41 \%$ in $10 \mathrm{~g}$ fresh leaves extract of $M$. alba. Maximum reduction in the radicle length by $P$. nigra extract was recorded $91.41 \%$ in $10 \mathrm{~g}$ fresh leaves extract, and a minimum reduction was observed $14 \%$ in $15 \mathrm{~g}$ dry leaves extract, whereas $15 \mathrm{~g}$ fresh leaves extract showed no germination. The data recorded from E. helioscopia extract showed that maximum reduction in the radicle length was observed $63.21 \%$ in $10 \mathrm{~g}$ dry leaves extract, and a minimum depletion in radicle length was observed in $42.14 \%$ in $15 \mathrm{~g}$ fresh leaves extract.

\section{Plumule length (cm)}

In (Fig. 3) it shows that the plumule length of $B$. campestris was reduced significantly by the aqueous extract of M. alba, P. nigra and E. helioscopia in all treatments except $15 \mathrm{~g}$ dry leaves extract of $P$. nigra which increased the plumule length $(28.34 \%)$. The graph revealed that maximum inhibition in plumule length was recorded $91.75 \%$ in $15 \mathrm{~g}$ dry leaves extract and minimum inhibition was recorded $59.45 \%$ in $5 \mathrm{~g}$ fresh leaves extract of $M$. alba. The extract of $P$. nigra reduced plumule length and was recorded a maximum of $91.90 \%$ in $10 \mathrm{~g}$ fresh leaves extract and a minimum of $2.42 \%$ in $5 \mathrm{~g}$ dry leaves extract. Maximum decreased in plumule length of $B$. campestris by $E$. helioscopia extract was observed $95.49 \%$ in $15 \mathrm{~g}$ dry leaves extract, and a minimum decrease of $66.21 \%$ was observed in $5 \mathrm{~g}$ fresh leaves extract. 
Khalid et al.

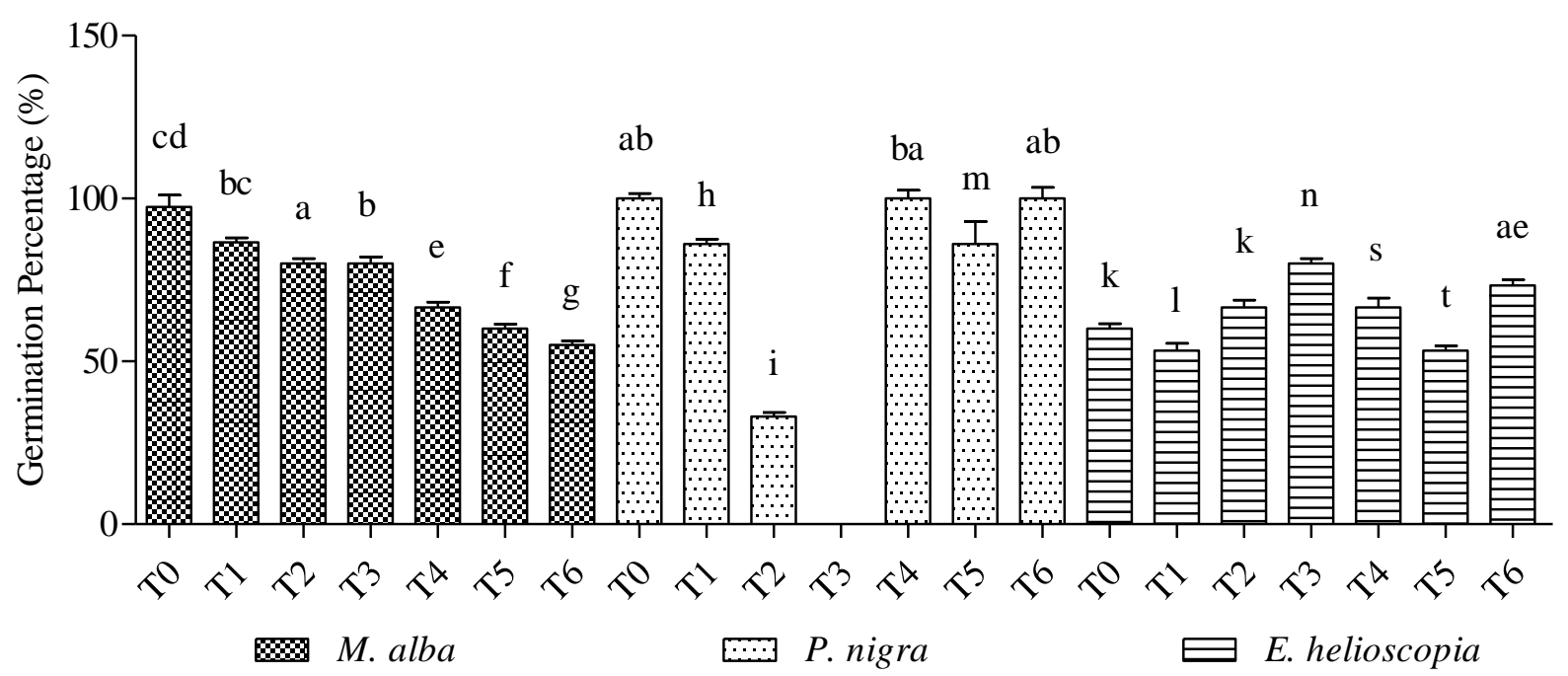

Figure 1. Effect of Morus alba, Populus nigra and Euphorbia helioscopia on germination percentage of Brassica campestris. $\mathrm{T} 0=\mathrm{Control}, \mathrm{T} 1=5 \mathrm{~g}$ fresh leaves extract, $\mathrm{T} 2=10 \mathrm{~g}$ fresh leaves extract, $T 3=15 \mathrm{~g}$ fresh leaves extract, $\mathrm{T} 4=5 \mathrm{~g}$ dry leaves extract, $\mathrm{T} 5=10 \mathrm{~g}$ dry leaves extract, $\mathrm{T} 6=15 \mathrm{~g}$ dry leaves extract. Bars with different letters represent significant difference at $P=0.05$

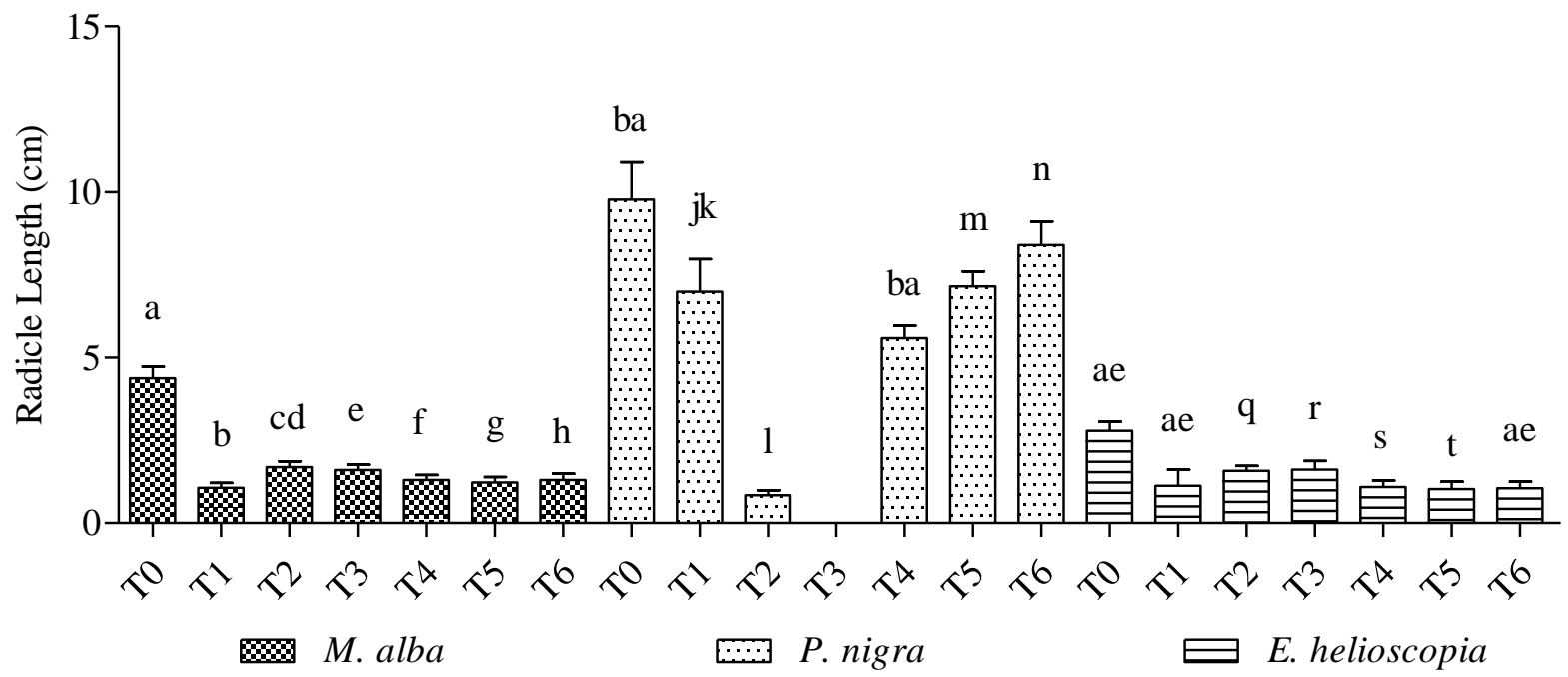

Figure 2. Effect of Morus alba, Populus nigra and Euphorbia helioscopia on radicle length of Brassica campestris. $\mathrm{T} 0=$ Control, $\mathrm{T} 1=5 \mathrm{~g}$ fresh leaves extract, $\mathrm{T} 2=10 \mathrm{~g}$ fresh leaves extract, $\mathrm{T} 3=15 \mathrm{~g}$ fresh leaves extract, $\mathrm{T} 4=5 \mathrm{~g}$ dry leaves extract, $\mathrm{T} 5=10 \mathrm{~g}$ dry leaves extract, $\mathrm{T} 6=\mathbf{1 5 g}$ dry leaves extract. Bars with different letters represent significant difference at $P=0.05$ 


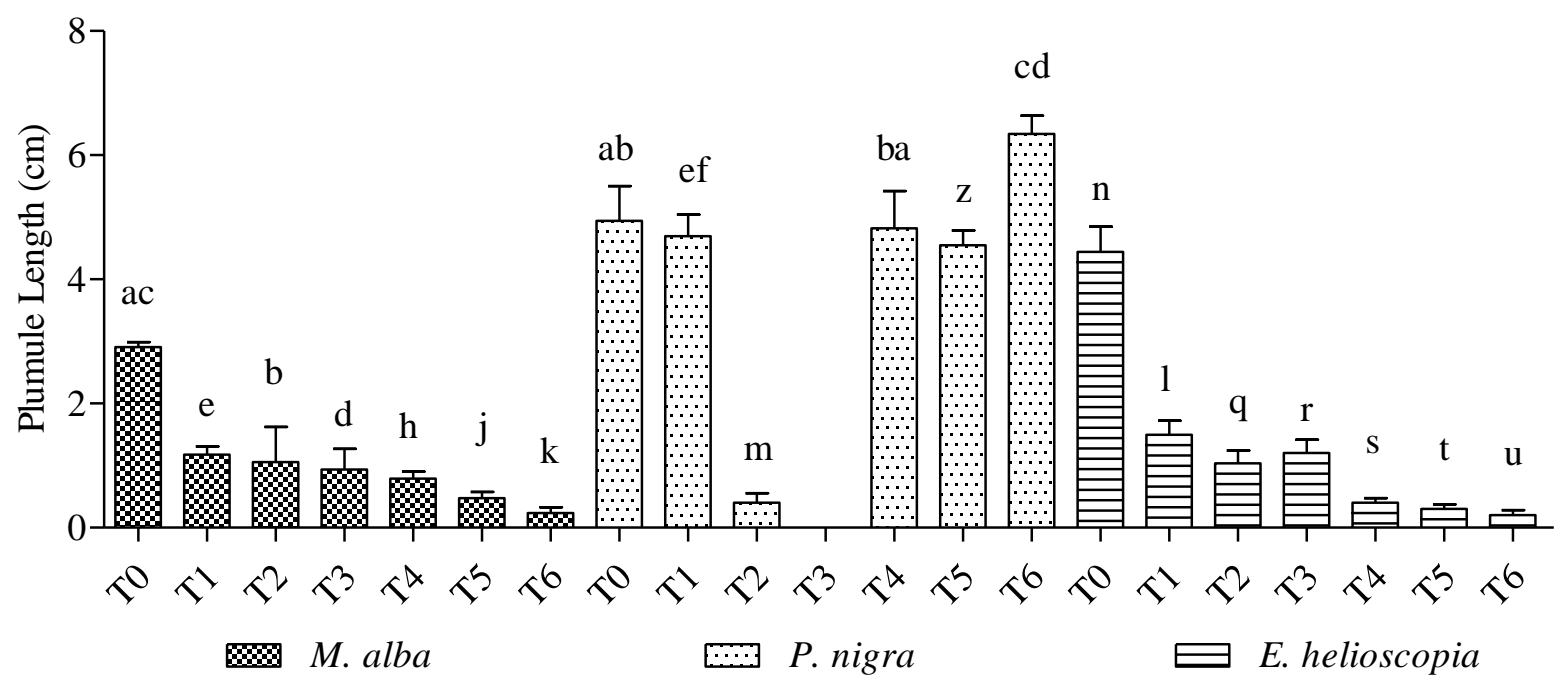

Figure 3. Effect of Morus alba, Populus nigra and Euphorbia helioscopia on plumule length of Brassica campestris. $\mathrm{T} 0=\mathrm{Control}, \mathrm{T} 1=5 \mathrm{~g}$ fresh leaves extract, $\mathrm{T} 2=10 \mathrm{~g}$ fresh leaves extract, $\mathrm{T3}=15 \mathrm{~g}$ fresh leaves extract, $\mathrm{T} 4=5 \mathrm{~g}$ dry leaves extract, $\mathrm{T} 5=10 \mathrm{~g}$ dry leaves extract, $\mathrm{T} 6=15 \mathrm{~g}$ dry leaves extract. Bars with different letters represent significant difference at $P=0.05$

\section{Discussion}

The present research work was performed to find out allelopathic effect of $M$. alba, $P$. nigra and E. helioscopia on Brassica campestris. It was found that both fresh and dry leaves extract increase the inhibitory effect. Maximum inhibition was recorded in $15 \mathrm{~g}$ followed by $10 \mathrm{~g}$ and $5 \mathrm{~g}$. Dry leaves extract had a more inhibitory effect than fresh leaves extract. The allelopathic effect of $M$. alba extract was more as compared to the effect of P. nigra and E. helioscopia extracts on Brassica campestris. The effect was more pronounced at high concentrations. The germination percentage of Brassica campestris was significantly effected by $M$. alba followed by $P$. nigra whereas, $E$. helioscopia extract showed less effect on germination percentage. The results showed similarity with the results of $\mathrm{Wu}$ [11], they concluded that the aqueous extract of Citrus reticulate Banco., Coronilla varia L., Eriobotrya japonica Thunb., Gynura bicolor DC., Hemerocallis citrine Baroni., Medicago sativa L., Morus alba L., Toona sinensis Roem., Zanthoxylum schinifolium Sieb significantly inhibited the seed germination and seedling growth of wheat. Similar results were found by Madany [12], they studied the Phytotoxicity of Euphorbia helioscopia L. on Triticum aestivum $\mathrm{L}$. and Pisum sativum $\mathrm{L}$. and found that E. helioscopia aqueous extract severely affected the germination in a concentration dependent manner. Our results also showed similarity with the results of Khan [13], they studied the Allelopathic Effect of Populus Nigra Bark on Zea Mays agroforestry ecosystems and found that the Populus nigra bark exhibits more effect on the germination percentage as compared to control. Similar results were also found by Khan [14] and Inayat [15]. The radicle and plumule length of Brassica campestris was significantly inhibited by $M$. alba, $P$. nigra and E. helioscopia extracts. Similar results were found by $\mathrm{Wu}$ [11]. The results are also in comparisons with the findings of Inayat [16], they studied Herbicidal Evaluation of the Aqueous Extract of Populus nigra L. Leaves on Six Weed Species and found Germination and growth of all six weeds species were reduced with increasing 
concentration of the leaves. Our findings were also in comparison with the results of Ning [17], they performed experiment on allelopathic effects of water extracts from stem and leaf of Euphorbia helioscopia on seed germination and seedling growth of three turfgrass species and found that water extract from E. helioscopia has the certain effect on tested lawn species. The germination rate, germination index, seedling height and root length of three lawn plant species show a gradual decline trend with increase of water extract compared with CK.

\section{Conclusion and Recommendations}

The present research work revealed that $M$. alba, $P$. nigra and E. helioscopia leaves may contain some allelochemicals that puts negative effect on the growth and germination of Brassica campestris and inhibited the germination, radicle and plumule length of Brassica campestris. It is recommended that Brassica campestris should not be grown in the fields containing $M$. alba, P. nigra and E. helioscopia. Fields that have M. alba, P. nigra and E. helioscopia their leaves should be removed before the sowing of Brassica campestris. Leaves should also be regularly removed during the fall season to avoid the crop from their allelopathic effects. People especially the farmers must be educated and informed about the negative effects of these plants. Resistant varieties are also a good tool for toleration of the allelopathic effects of plants so such varieties should be sown, that are resistant to the allelopathic effects of $M$. alba, $P$. nigra and $E$. helioscopia in the field containing $M$. alba, P. nigra and E. helioscopia. The allelopathic compatibility of crops with plants should be checked before introducing them in the field.

\section{Authors' contributions}

Conceived and designed the experiments: $\mathrm{S}$ Khalid, Amreen \& S Bibi, Performed the experiments: Amreen, S Bibi, SA Taskeen \& H Shumail, Analyzed the data: S Khalid \&
SIU Haq, Contributed reagents/ materials/ analysis tools: Amreen, S Bibi, SA Taskeen \& H Shumail, Wrote the paper: S Khalid \& SIU Haq.

\section{References}

1. Molisch H (1937) Der Einfluss einer Pflanze auf die andere: Allelopathie. Jena, Germany Gustav Fischer. pp. 20.

2. Rice EL (1984). "Allelopathy". 2nded. Academic press, New York.

3. Radosevich SR, JS Holt \& C Ghersa (2007). Ecology of weeds and invasive plants relationship to agriculture and natural resource management. New York: Wiley; pp. 454.

4. Albuquerque MBD, RCD Santos, LM Lima, PDAM Filho, RJMC Nogueira, CAGD Camara \& ADR Ramas (2011). Allelopathy an alternative tool to improve cropping systems. A review. Agron Sustain Dev 31(2): 379-395.

5. Echinberg D, C Ristock, W Kroeber \& H Bruelheide (2014). Plant polyphenolsimplication of different sampling, storage and sample processing in biodiversity ecosystem functioning experiments. J Chem Ecol 30(7): 676692.

6. Krochmal A (1954). The vanishing white mulberry of northern Greece. Econ Bot 8(2): 145-151.

7. Broeck AV (2003). Euforgen Technical Guidelines for genetic conservation and use for European black poplar (Populus nigra). International Plant Genetic Resources Institute 1-6.

8. Cours BJ \& PH Williams (1977). Genetic studies in Brassica campestris. Plant Breeding Abstract 51: 1533-1536.

9. Husain F, SS Gilani, I Fatima \& MJ Durrani (2003). Some autecological studies on Amaranthus viridis L. Pak J of Weed Sci Res 9(1-2): 117-124

10. Lopez ML, NE Bozani \& JA Zygadlo (2008). Allelopathic potential of Tagetes minuta terpenes by a chemical, 
anatomical and phytotoxic research. Biochem Syst Ecol 36(12): 882-890.

11. Wu Y, Cheng Xu, Cai Q \& Lin C (2012). Allelopathic effects of twelve hedgerow plant species on seed germination and seedling growth of wheat (Triticum astivum L). Adv Mat Res 356-360: 27672773.

12. Madany MMY \& Saleh AM (2015). Phytotoxicity of Euphorbia helioscopia L. on Triticum aestivum L. and Pisum sativum L. Ann Agric Sci 60(1): 141-151.

13. Khan M, Zakaria M, Ali F, Hussain F, Imdadullah \& Musharaf S (2016). Allelopathic Effect of Populus Nigra Bark on Zea Mays in Agroforestry Ecosystems. Global J of Sci Frontier Res: (C) Biol Sci 16(1): 21-27.

14. Khan M \& Musharaf S (2016). Allelopathic effect of Black poplar
(Populus nigra L.) On cultivated plant. Pak J Bot, pp. 1-14.

15. Inayat $N$, Muhammad Z, Rehmanullah \& Majeed A (2020). Phytochemical screening and allelopathic evaluation of aqueous and methanolic leaf extracts of Populus nigra L. Pure Appl Biol 9(1): 1242-1249.

16. Inayat $\mathrm{N}$, Muhammad $\mathrm{Z}$, Khan $\mathrm{R}$, Quradha MM, Ullah R \& Majeed A (2019). Herbicidal Evaluation of the Aqueous Extract of Populus nigra L. Leaves on Six Weed Species. Turkish J of Weed Sci 22(2): 153-157.

17. Ning N, Lei W, Di FM, Li YM \& Lin ZX (2015). Allelopathic effects of water extracts from stem and leaf of Euphorbia helioscopia on seed germination and seedling growth of three turfgrass species. Guizhou Agric Sci 43(5): 54-57. 